\title{
TIPOS E DOSES DE CALCÁRIO NAS CARACTERÍSTICAS AGRONÔMICAS DE Panicum maximum Jacq. cv. TOBIATÃ EM FUNÇÃO DOS MÉTODOS DE APLICAÇÃO
}

\author{
Pedro Henrique de Cerqueira Luz ${ }^{1 *}$; Valdo Rodrigues Herling1; Gustavo José Braga4; Godofredo \\ César Vitti; César Gonçalves de Lima \\ ${ }^{1}$ Depto. de Zootecnia - USP/FZEA, C.P. 23 - CEP: 13635-900 - Pirassununga, SP. \\ ${ }_{2}^{2}$ Depto.de Solos e Nutrição de Plantas - USPIESALQ, C.P. 9 - CEP: 13418-900 - Piracicaba, SP. \\ ${ }^{3}$ Depto de Ciências Básicas - USP/FZEA. \\ ${ }^{4}$ Bolsista FAPESP. \\ *Autor correspondente <phcerluz@usp.br>
}

RESUMO: As características agronômicas da pastagem dependem da qualidade do solo. Neste trabalho foram avaliados os efeitos de tipos e doses de calcário, com e sem incorporação, em algumas características agronômicas de uma pastagem degradada de Panicum maximum Jacq. cv. Tobiatã, num Latossolo Vermelho distrófico. As avaliações ocorreram durante quatro cortes consecutivos no período das chuvas ("verão") de 1995/96 e um corte no período seco ("inverno") em 1996. A produção de matéria seca do capim-Tobiatã aumentou com o método de incorporação com grade, devido ao efeito mecânico, porém não respondeu aos tipos e doses de calcário, sendo observadas as maiores produções no $4^{\circ}$ corte ("verão"). Foram observados aumentos na cobertura de solo pela planta forrageira para os cortes de verão, com decréscimo no de inverno, porém com valor superior ao do início de verão, enquanto que a área de solo descoberto apresentou comportamento oposto permanecendo constante a participação das plantas invasoras. Na avaliação de perfilhamento encontrou-se resposta à incorporação, sendo consistente com os dados de produção.

Palavras-chave: composição botânica, pastagem degradada, perfilhamento, meristema apical

\section{TYPES AND RATES OF LIME AND THE AGRONOMIC CHARACTERISTICS OF TOBIATÃ GRASS (Panicum maximum Jacq.) AS A FUNCTION OF APPLICATION METHODS}

\begin{abstract}
Agronomic characteristics of pastures depend on soil quality. This work studies the effects of types and rates of limestone, with or without incorporation, on the physiological aspects (botanic composition and tillering) and productivity of a degraded Guinea grass (Panicum maximum Jacq. cv. Tobiatã) pasture, on an Hapludox. Samples stem from four consecutive cuttings during the 1995/96 summer and one cutting from the winter of 1996. Types and rates of limestone had no effect on dry matter yield; however, incorporation into the soil with harrow was effective. The soil cover increased in summer cuttings, and decreased in the winter, but the highest value was observed for the $4^{\circ}$ cutting in the beginning of the summer, while the uncovered soil area presented an opposite behavior, without changes for weeds plants. Tiller evaluation did not present response to liming, but for incorporation with harrow, being consistent with yield data of productivity.

Key words: botanic composition, degraded pasture, spronting, apical meristem
\end{abstract}

\section{INTRODUÇÃO}

A pastagem pode ser considerada como degradada quando houver queda acentuada em sua produtividade potencial, decorrente das condições edáficas e climáticas a que está submetida. A perda de fertilidade do solo, a invasão de plantas indesejáveis e o manejo inadequado são os principais fatores que levam à degradação (Spain \& Gualdron, 1991).

A recuperação direta de pastagens de braquiárias pode ser feita mediante o suprimento adequado de corretivos e fertilizantes em deficiência, sendo aplicados na superfície ou então incorporados (Zimmer et al., 1994).

Nos últimos anos surgiram no mercado diversos tipos de calcário, com diferentes processos de produção, que basicamente envolvem granulometria fina e/ou a calcinação, gerando a necessidade de se avaliar os efeitos da qualidade desses corretivos sobre o solo e a planta. No estudo da correção do solo para as plantas forrageiras, em termos de elevação da saturação por bases $(\mathrm{V} \%)$, deve-se considerar a sua resposta à calagem. Werner et al. (1996) dividiram as gramíneas em três grupos, sendo o primeiro mais exigente, como é o caso do capim-Tobiatã (Panicum maximum Jacq. cv. Tobiatã), onde os autores sugerem elevar a $\mathrm{V} \%$ a $70 \%$ na implantação e a $60 \%$ na manutenção.

Existe a necessidade de incorporar os calcários, uma vez que as operações de preparo do solo para as culturas normalmente são superficiais, e, portanto, não conseguem proporcionar uma adequada mistura do corretivo com o solo, lembrando que normalmente os 
calcários apresentam baixa solubilidade (Quaggio, 1985). Desta forma, o fato de utilizar-se de corretivos mais ou menos reativos, implica em diferente predisposição na resposta da planta. As gramíneas com hábito de crescimento estolonífero e ou rizomatoso, facilitam o processo de incorporação do corretivo, quando comparadas com as de crescimento cespitoso, como é o caso do capim-Tobiatã (Vitti \& Luz, 1997).

Num estudo de estratégias de recuperação de uma pastagem de Brachiaria decumbens Stapf., Soares Filho (1991) encontrou resultado desfavorável para o uso da gradagem exclusiva, que se igualou à testemunha no segundo ano, quando comparada ao tratamento com macro e micronutrientes para a produção de matéria seca acumulada no primeiro ano.

A ação da grade, sob o ponto de vista da incorporação de insumos e danos à planta, pode levar a diferentes resultados, dependendo do tipo de solo, do hábito de crescimento da planta forrageira e das dimensões e condição de operação da grade. No caso de uma espécie de crescimento rizomatoso/estolonífero, em solo arenoso, usando-se uma grade aradora (por exemplo, 14 discos de $61 \mathrm{~cm}$ ) esta conduzirá a maior mobilização mecânica do solo, e portanto melhor incorporação do insumo, porém certamente provocará danos à planta forrageira. Por outro lado, uma incorporação leve (grade de 16 discos de $41 \mathrm{~cm}$ ) num solo argiloso será menos prejudicial ao desenvolvimento da planta.

Sob o ponto de vista da recuperação da pastagem considera-se como importante a retomada da produtividade, o que está relacionado com a composição botânica da pastagem. A grande diversidade de espécies na maioria dos sistemas naturais de vegetação tropical e subtropical fornece uma rica fonte de variabilidade, cujos padrões de resposta podem ser conhecidos através de mudanças na composição botânica ao longo do tempo. Tais espécies, dependendo do manejo a que são submetidas, podem tornar-se dominantes, subdominantes ou invasoras nas pastagens. O conhecimento dessas variações é imperioso, de modo a preservar as espécies desejáveis, mantendo a mais favorável e produtiva composição botânica nestes sistemas naturais (Cóser et al., 1991). A estabilidade da pastagem deve sempre ser levada em consideração no aumento da produção e da qualidade da planta forrageira. Por esta razão, a persistência da espécie deve ser considerada como dos mais valiosos atributos de uma pastagem (Rodrigues, 1986).

Num experimento em que foram testados dois níveis de calagem $\left(1,500\right.$ e $3,375 \mathrm{t} \mathrm{ha}^{-1}$ de calcário magnesiano) numa pastagem estabelecida de capimcolonião, por três anos consecutivos, Werner et al. (1979) não observaram resposta em produção de matéria seca, inclusive com efeito depressivo no $2^{\circ}$ ano do experimento.
Ao avaliarem as limitações nutricionais do capimcolonião, Ferrari Neto et al. (1994) concluíram que a omissão de $\mathrm{Ca}$ e $\mathrm{Mg}$, bem como a adição de calcário para elevar a $\bigvee$ a $60 \%$, não favoreceram a produção de matéria seca.

Num estudo com oito cultivares de Panicum maximum Jacq., Cecato et al. (1996) observaram que o cultivar Tobiatã, no período do verão, apresentou produção de matéria seca total e teores de proteína bruta da ordem de $6988 \mathrm{~kg} \mathrm{ha}^{-1}$ e $11,60 \%$ respectivamente. Para o período de inverno os valores foram $2916 \mathrm{~kg} \mathrm{ha}$ ${ }^{1}$ de matéria seca total e $9,58 \%$ de proteína bruta.

O perfilhamento em Panicum maximum (cvs. Tobiatã, Tanzânia, Mombaça e Colonião), avaliado após corte, por Barbosa et al. (1996) respondeu positivamente à decapitação de perfilhos, sendo maior esta resposta para perfilhos aéreos em relação aos basais em função da eliminação do meristema apical. No mesmo experimento, os autores verificaram a influência da eliminação do meristema apical no perfilhamento, obtendo-se uma correlação positiva significativa entre decapitação e número de perfilhos que surgiram nas três primeiras semanas após o corte, evidenciando-se o efeito inibidor do meristema apical sobre a ativação das gemas aéreas e basais, fator mais importante na determinação do vigor de rebrota. Segundo Ferrari Neto et al. (1994), o capim-colonião avaliado na ausência e presença de calcário não apresentou variação em seu número de perfilhos.

Favoretto et al. (1987), na avaliação dos efeitos da eliminação do meristema apical, do capim-colonião, na produção de matéria seca, observaram que os cortes mais produtivos conduziram a maior taxa de eliminação do meristema apical, em decorrência da elevação do mesmo. Num estudo semelhante, com o capim-Tobiatã, em Rondônia, Costa \& Oliveira (1997) constataram que o aumento da idade das plantas implicou em maiores produções de matéria seca. No entanto ocorreu aumento da eliminação dos meristemas apicais e diminuição do vigor de rebrota.

Num estudo de Herling (1995) a densidade de perfilhos apresentou comportamento inversamente proporcional ao peso médio de perfilhos para os capins Colonião e Centenário, ou seja, maior densidade estava associada ao menor peso médio deles. Pôde-se constatar, ainda, que houve maior correlação da produção de matéria seca com a densidade de perfilhos em detrimento de seu peso médio, ressaltando-se que esse comportamento foi devido ao recém estabelecimento das cultivares. Número e peso dos perfilhos variam inversamente, mas o rendimento forrageiro revela elevada correlação com o peso de perfilhos (Gomide \& Gomide, 1996).

O objetivo desse estudo foi verificar os efeitos de diferentes tipos e doses de calcário, com e sem incorporação, sobre algumas características agronômicas do capim-Tobiatã (Panicum maximum Jacq.) em uma pastagem degradada. 


\section{MATERIAL E MÉTODOS}

O experimento foi instalado em Latossolo Vermelho Escuro, argiloso, distrófico, localizado no Campus da USP de Pirassununga - SP, latitude sul $21^{\circ} 59^{\prime}$, longitude oeste $47^{\circ} 26^{\prime}$, a $634 \mathrm{~m}$ de altitude. O clima da região, de acordo com a classificação de Köeppen, é do tipo Cwa (clima tropical de altitude, com inverno seco e verão quente e chuvoso), segundo Oliveira \& Prado (1994).

Os atributos químicos obtidos na análise de caracterização da área evidenciaram baixa fertilidade do solo $\left(\mathrm{pH}_{\mathrm{CaCl}}\right)=4,1 ; \mathrm{Ca}=9,0 \mathrm{mmol}_{\mathrm{c}} \mathrm{dm}^{-3} ; \mathrm{Mg}=3,0 \mathrm{mmol}_{\mathrm{c}}$ $\mathrm{dm}^{-3} ; \mathrm{Al}=8,0 \mathrm{mmol}_{\mathrm{c}} \mathrm{dm}^{-3} ; \mathrm{V}=15 \% ; \mathrm{CTC}=85 \mathrm{mmol}_{\mathrm{c}} \mathrm{dm}^{-3}$, $\mathrm{m}=39 \%$ ) que, associados ao fato do capim-Tobiatã ter sido implantado há cerca de treze anos e aos aspectos inadequados de manejo da pastagem, correção e adubação de formação, conduziram a uma situação de pastagem considerada degradada.

A pesquisa teve início em fevereiro de 1995, com a aplicação de calcário, após rebaixamento mecânico a 20 $\mathrm{cm}$ e posterior incorporação apenas nas subparcelas respectiva ao método de aplicação. Na primavera subsequente foi feita a uniformização e adubação da pastagem com $120 \mathrm{~kg} \mathrm{ha}^{-1}$ de $\mathrm{P}_{2} \mathrm{O}_{5}, 50 \mathrm{~kg} \mathrm{ha}^{-1}$ de $\mathrm{N}$ e 50 $\mathrm{kg} \mathrm{ha}^{-1}$ de $\mathrm{K}_{2} \mathrm{O}$. Foram realizados quatro cortes de "verão" com intervalo de 35 dias entre cortes e um corte de inverno. Após cada corte as parcelas receberam, em cobertura, 50 $\mathrm{kg} \mathrm{ha}{ }^{-1}$ de $\mathrm{N}$ e de $\mathrm{K}_{2} \mathrm{O}$, com exceção do $4^{\circ}$ e $5^{\circ}$ cortes.

$\mathrm{O}$ delineamento foi em blocos ao acaso com quatro repetições e o experimento em parcelas subdivididas, sendo que tipo e dose de calcário estudados corresponderam às parcelas e o método de aplicação às subparcelas. As parcelas mediam 6,0 metros de largura e 8,0 metros de comprimento $\left(48 \mathrm{~m}^{2}\right)$ sendo subdividida na largura para o fator incorporação, ficando desta forma a subparcela com $3,0 \times 8,0$ metros $\left(24 \mathrm{~m}^{2}\right)$. Adotou-se uma bordadura de $0,5 \mathrm{~m}$ em todo o perímetro das subparcelas, e uma faixa de caminhamento de 1,0 m entre as parcelas no bloco, de forma tal que cada subparcela ficou com 14 $\mathrm{m}^{2}$ de área útil.

Os calcários utilizados nas aplicações foram os seguintes: Calcário Calcinado $(45 \%$ de $\mathrm{CaO}, 25 \%$ de MgO, Poder de Neutralização - PN $=132 \%$, Reatividade - RE $=100 \%$ e Poder Relativo de Neutralização Total PRNT $=132 \%)$ e Calcário Tradicional (43\% de CaO, 9\% de $\mathrm{MgO}, \mathrm{PN}=99,3 \%, \mathrm{RE}=91 \%$ e PRNT $=90 \%$ ).

As doses empregadas para os tratamentos de calagem foram atribuídas de acordo com o método de elevação da saturação por bases (Raij, 1981): Testemunha $=0 \mathrm{t} \mathrm{ha}^{-1}$; Calcinado $\mathrm{V}_{40 \%}=1,61 \mathrm{t} \mathrm{ha}^{-1}$; Calcinado $\mathrm{V}_{60 \%}=2,90 \mathrm{t} \mathrm{ha}^{-1}$; Tradicional $\mathrm{V}_{40 \%}=2,36 \mathrm{t} \mathrm{ha}^{-1}$; Tradicional $\mathrm{V}_{60 \%}=4,25 \mathrm{t} \mathrm{ha}^{-1}$. Após a aplicação dos calcários foi realizada a incorporação em metade das subparcelas, utilizando-se de uma grade "leve", com 16 discos de 16", na posição destravada, com as seções paralelas, incorporando superficialmente o calcário a 5,0 $\mathrm{cm}$ de profundidade.
A composição botânica foi efetuada em três pontos dentro de cada subparcela, através do lançamento aleatório de um quadrado $\left(0,25 \mathrm{~m}^{2}\right)$, determinando-se visualmente as áreas ocupadas pela planta forrageira, invasoras e solo descoberto (Toledo \& Schultze-Kraft, 1982).

O perfilhamento também foi avaliado nas subparcelas, em local fixo, usando-se a área de 0,125 $\mathrm{m}^{2}$, ficando a estaca localizada em seu centro. Após a contagem dos perfilhos, fez-se o corte da touceira, que levada à estufa à $65^{\circ} \mathrm{C}$ por 72 horas e pesada, possibilitou a determinação do peso seco da touceira e do peso seco médio de perfilho. Uma semana após o corte fez-se a contagem de perfilhos decapitados, calculando-se a porcentagem de eliminação de meristema apical.

$\mathrm{O}$ corte foi realizado à altura aproximada de 15 $\mathrm{cm}$ do solo, de forma manual, sendo a produção de matéria verde pesada imediatamente após o corte. $\mathrm{O}$ teor de matéria seca foi determinado através de uma amostra da forragem retirada do material cortado de cada subparcela, a qual foi secada em estufa com ventilação forçada a $65^{\circ} \mathrm{C}$ por 72 horas (AOAC, 1975). A produção de matéria seca a $65^{\circ} \mathrm{C}$ foi calculada pela multiplicação do teor de matéria seca pela produção de matéria verde.

Os resultados foram analisados utilizando-se o procedimento GLM do programa estatístico SAS ${ }^{\circledR}$ (1989), adotando-se nível de significância de $5 \%$.

\section{RESULTADOS E DISCUSSÃO}

As produções de matéria seca do capim-Tobiatã, obtidas em cada corte, não variaram $(P>0,05)$ com o tipo e doses de calcário (Tabela 1), estando de acordo com Werner et al. (1979), que não constataram resposta à calagem para a produção de matéria seca, assim como aos obtidos por Ferrari Neto et al. (1994) num estudo de limitações nutricionais, ambos avaliando o capim-colonião.

Para métodos de aplicação detectou-se efeito positivo $(P<0,05)$, obtendo-se as maiores produções na condição incorporada, com uma média de $1791 \mathrm{~kg} \mathrm{ha}^{-1}$ contra $1604 \mathrm{~kg} \mathrm{ha}^{-1}$ sem incorporação para os cinco cortes, contrariamente aos resultados de Soares Filho (1991) para braquiária submetida a incorporação com grade aradora.

A produção obtida no verão totalizou $7441 \mathrm{~kg} \mathrm{MS}$ $\mathrm{ha}^{-1}$, para quatro cortes, sendo semelhante ao observado por Werner et al. (1979) num estudo de calagem com capim-colonião quando obtiveram $7987 \mathrm{~kg} \mathrm{MS} \mathrm{ha-1}$, porém com cinco cortes.

Houve interação de cortes $\times$ métodos de aplicação $(P<0,05)$, porém a incorporação foi considerada eficiente a partir do $2^{\circ}$ corte. No decorrer dos cortes, constatou-se no estudo de correlação (Figuras 1 e 2) que o peso médio de perfilhos foi mais determinante na produção de matéria seca quando o calcário não foi incorporado $(r=0,84)$ do que quando foi $(r=0,77)$, e que a densidade de perfilhos 
correlacionou-se melhor com a produção de matéria seca também na condição sem incorporação ( $r=0,79$ vs. $r=0,51$ ). Desta forma, a utilização de grade para a incorporação do calcário concorreu para diminuir a densidade de perfilhos, o que implicou num maior peso médio dos perfilhos sobreviventes (Gomide \& Gomide, 1996).

$\mathrm{Na}$ avaliação do perfilhamento (Tabela 2) não se detectou resposta para os tipos e doses de calcário, para as variáveis analisadas, concordando com os resultados de Ferrari Neto et al. (1994), que avaliando a ausência de Ca e Mg no solo, e a adição de calcário para se elevar a saturação por bases a $60 \%$, observaram que a densidade de perfilhos do capim-colonião não foi afetada.

Observando-se as percentagens médias de eliminação do meristema apical, nota-se que a incorporação conduziu a maior eliminação dos mesmos (Tabela 2), uma vez que o montante de produção era maior, sendo coerente com a variação da densidade e peso médio $(P<0,05)$, sem, contudo, apresentar resposta para os tipos e doses de calcário. No entanto, verificaram-se diferenças entre cortes $(P<0,05)$, sendo o $2^{\circ}$ e $4^{\circ}$ semelhantes, porém diferentes dos demais. Esse comportamento deveu-se aos processos de alongamento dos colmos e florescimento, principalmente por ocasião do $4^{\circ}$ corte.

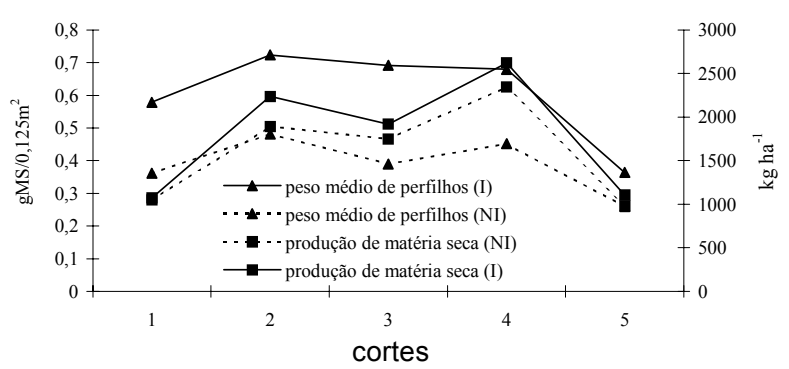

Figura 1 - Produção de matéria seca e Peso médio de perfilhos nas condições Incorporada (I) e Não Incorporada (NI).
Os cortes mais produtivos apresentaram uma taxa mais elevada de eliminação de meristema apical $(6,75 \%$ no $2^{\circ}$ corte e $10,25 \%$ no $4^{\circ}$ corte), semelhante aos resultados de Favoretto et al. (1987) com o capim-colonião.

Os cortes de "verão" (7441 kg ha-1 de MS), em média, corresponderam a $88 \%$ do total produzido (8486 $\mathrm{kg} \mathrm{ha}^{-1}$ de MS), indicando acentuada estacionalidade, uma vez que o corte de inverno representou apenas $12 \%$ do total (1045 kg ha-1 de MS), resultados diferentes dos alcançados por Cecato et al. (1996) com o capim-Tobiatã, em Maringá - PR, que em três cortes de verão produziu $6988 \mathrm{~kg} \mathrm{MS} / \mathrm{ha}(71 \%)$ e $2916 \mathrm{~kg} \mathrm{ha}^{-1}$ de MS para o período de inverno $(29 \%)$, porém em dois cortes.

Para a composição botânica também não se observou resposta para os tipos e doses de calcário, bem como para métodos de aplicação $(P>0,05)$. Por outro lado, para os cortes, foram observadas diferenças significativas com aumento da cobertura do solo pela planta forrageira e redução da área de solo descoberto, permanecendo constante a participação das plantas invasoras (Tabela 3). Os contrastes entre os cortes de verão e o de inverno foram significativos apenas para a planta forrageira e solo descoberto. Os resultados apontam para a recuperação da pastagem, que

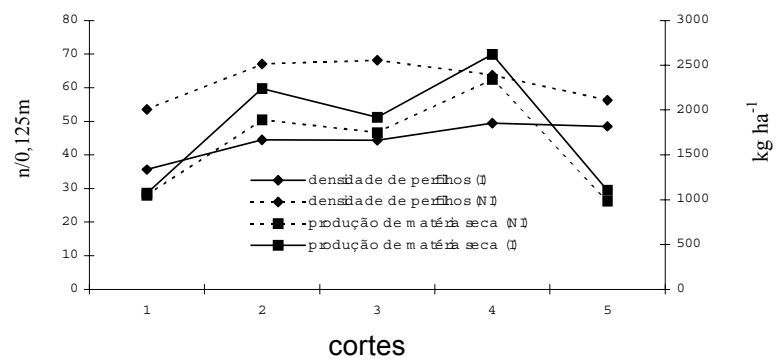

Figura 2 - Produção de matéria seca e densidade de perfilhos nas condições Incorporada (I) e Não Incorporada (NI).

Tabela 1 - Produção de matéria seca* do capim-Tobiatã para épocas de corte, tipos e doses de calcário e incorporação.

\begin{tabular}{|c|c|c|c|c|c|c|c|c|c|c|c|c|c|}
\hline \multirow{3}{*}{ Tratamento } & \multicolumn{5}{|c|}{ Incorporado } & \multicolumn{7}{|c|}{ Não Incorporado } & \multirow{3}{*}{$\begin{array}{l}\text { méd- } \\
\text { ia } \\
\text { geral }\end{array}$} \\
\hline & & & Corte & & & \multirow{2}{*}{ média } & \multicolumn{5}{|c|}{ Corte } & \multirow{2}{*}{ média } & \\
\hline & $21 / 12$ & $25 / 01$ & $28 / 02$ & 02/04 & $12 / 06$ & & $21 / 12$ & $25 / 01$ & $28 / 02$ & $02 / 04$ & $12 / 06$ & & \\
\hline & \multicolumn{13}{|c|}{ - } \\
\hline Testemunha & 1021 & 2297 & 1967 & 2809 & 1183 & 1855 & 1055 & 1777 & 1698 & 2279 & 884 & 1539 & 1697 \\
\hline Calcina do $40 \%$ & 951 & 2350 & 1871 & 2436 & 1052 & 1732 & 1092 & 1927 & 1872 & 2346 & 978 & 1643 & 1687 \\
\hline Calcina do $60 \%$ & 1067 & 2430 & 1849 & 2415 & 1049 & 1762 & 1015 & 1766 & 1546 & 2245 & 971 & 1509 & 1635 \\
\hline Tra dicional $40 \%$ & 1133 & 2174 & 1996 & 2735 & 1092 & 1826 & 937 & 1799 & 1769 & 2337 & 1041 & 1577 & 1701 \\
\hline Tradiciona $60 \%$ & 1183 & 1935 & 1911 & 2711 & 1156 & 1779 & 1147 & 2195 & 1855 & 2514 & 1045 & 1751 & 1765 \\
\hline Média & $1071 d$ & $2237 \mathrm{~b}$ & $1919 \mathrm{c}$ & $2621 \mathrm{a}$ & $1106 \mathrm{~d}$ & $1791 \mathrm{~A}$ & $1049 \mathrm{c}$ & $1893 \mathrm{~b}$ & $1748 b$ & $2344 a$ & $984 \mathrm{c}$ & $1604 \mathrm{~B}$ & 1697 \\
\hline
\end{tabular}

Médias na linha, seguidas de mesma letra, maiúscula e minúscula não diferem pelo teste de Tukey $(\mathrm{P}>0,05)$.

Tabela 2 - Alguns atributos da planta em cinco cortes.

\begin{tabular}{|c|c|c|c|c|c|c|c|}
\hline \multirow{2}{*}{ Atributo } & \multicolumn{5}{|c|}{ Corte } & \multicolumn{2}{|c|}{ Incorporação } \\
\hline & $21 / 12$ & $25 / 01$ & $28 / 02$ & $02 / 04$ & $12 / 06$ & COM & SEM \\
\hline Densidade de perfilhs & $44,6 \mathrm{~b}$ & $55,8 a$ & $56,3 a$ & $56,6 \mathrm{a}$ & $52,4 a b$ & $44,90 \mathrm{~B}$ & $61,80 \mathrm{~A}$ \\
\hline$\% \mathrm{EMA}^{*}$ & $3,35 \mathrm{~b}$ & $6,75 a b$ & $4,05 \mathrm{~b}$ & $10,25 a$ & $4,70 \mathrm{~b}$ & $6,58 \mathrm{~A}$ & $5,06 \mathrm{~B}$ \\
\hline Peso Médio de Perfilho (g) & $0,470 \mathrm{ab}$ & $0,675 a$ & $0,541 \mathrm{a}$ & $0,565 a$ & $0,314 b$ & $0,626 \mathrm{~A}$ & $0,399 \mathrm{~B}$ \\
\hline
\end{tabular}

Médias na linha, seguidas de mesma letra, minúscula e maiúscula, não diferem pelo teste de Tukey $(P>0,05)$.

*Eliminação do meristema apical 
Tabela 3 - Composição botânica em cinco cortes e nível de significância.

\begin{tabular}{lcccccr}
\hline \multirow{2}{*}{ Variável } & \multicolumn{5}{c}{ Corte } & \multirow{2}{*}{ Média } \\
\cline { 2 - 5 } & $21 / 12$ & $25 / 01$ & $28 / 02$ & $02 / 04$ & $12 / 06$ & \\
\hline \% planta forrageira & $45,95 \mathrm{c}$ & $51,9 \mathrm{bc}$ & $61,8 \mathrm{a}$ & $68,35 \mathrm{a}$ & $61,30 \mathrm{ab}$ & 56,62 \\
\% solo descoberto & $49,15 \mathrm{a}$ & $44,05 \mathrm{a}$ & $32,75 \mathrm{~b}$ & $26,2 \mathrm{~b}$ & $31,85 \mathrm{~b}$ & 36,80 \\
\% planta invasora & 4,90 & 6,30 & 5,50 & 5,50 & 5,90 & 5,62 \\
\hline
\end{tabular}

Médias na linha, seguidas de mesma letra minúscula não diferem pelo teste de Tukey $(P>0,05)$.

provavelmente está associada com a melhoria das condições nutricionais da planta, decorrente da adubação.

\section{CONCLUSÕES}

A produção de matéria seca do capim-Tobiatã aumentou com o método de incorporação com grade, porém não respondeu aos tipos e doses de calcário. $\mathrm{O}$ peso médio de perfilhos foi mais determinante para a produção de matéria seca do que o número de perfilhos, quando da incorporação do calcário.

\section{AGRADECIMENTO}

À FAPESP pelo financiamento do projeto e pela concessão de uma bolsa de iniciação científica no período de maio/96 a julho/97.

\section{REFERÊNCIAS BIBLIOGRÁFICAS}

ASSOCIATION OF OFFICIAL ANALITICAL OF CHEMISTS. Official methods of analysis of the AOAC. 12.ed. Washington: AOAC, 1975. 1094p.

BARBOSA, M.A.A.F.; DAMASCENO, J.C.; CECATO, U.; SAKAGUTI, E.S. Estudo de perfilhamento em quatro cultivares de Panicum maximum Jacq. submetidos a duas alturas de corte. In: REUNIÃO ANUAL DA SOCIEDADE BRASILEIRA DE ZOOTECNIA, 33., Fortaleza, 1996. Anais. Fortaleza: SBZ, 1996. p.106-108.

CECATO, U.; BARBOSA, M.A.A.F.; SAKAGUTI, E.S.; DAMASCENO, J.C.; SUZUKI, E.; MEURER, F. Avaliação de cultivares de Panicum maximum Jacq. In: REUNIÃO ANUAL DA SOCIEDADE BRASILEIRA DE ZOOTECNIA, 33., Fortaleza, 1996. Anais. Fortaleza: SBZ, 1996. p.109-111.

CÓSER, A.C.; NASCIMENTO JR., D.; GOMIDE, J.A.; SILVA, J.F.C.; SILVA, M.A.; GARCIA, R.; MARTINS, C.E. Utilização do botanal em comparação a outros métodos de avaliação, em pastagens naturais. Pesquisa Agropecuária Brasileira, v.26, p.759-767, 1991.

COSTA, N.L.; OLIVEIRA J.R.C. Produção de forragem e composição química de Panicum maximum cv. Tobiatã em diferentes idades de cortes. In: REUNIÃO ANUAL DA SOCIEDADE BRASILEIRA DE ZOOTECNIA, 34., Juiz de Fora, 1997. Anais. Juiz de Fora: SBZ, 1997. p.222-224.

FAVORETTO, V.; TONINI JR., R.; REIS, R.A.; RODRIGUES, L.R.A. Efeito da altura e freqüência de corte sobre a produção, composição bromatológica e vigor de rebrota do capimColonião. Pesquisa Agropecuária Brasileira, v.22, p.12791285, 1987.

FERRARI NETO, J.; FAQUIN, V.; VALE, F.R.; EVANGELISTA, A.R. Limitações nutricionais do Colonião (Panicum maximum Jacq.) e da Braquiária (Brachiaria decumbens Stapf), em amostras de um latossolo do noroeste do Paraná: I.Produção de matéria seca e perfilhamento. Revista da Sociedade Brasileira de Zootecnia, v.23, p.538-551, 1994.
GOMIDE, C.A.M.; GOMIDE, J.A. Morfogênese e análise de crescimento de cultivares de Panicum maximum. In: REUNIÃO ANUAL DA SOCIEDADE BRASILEIRA DE ZOOTECNIA, 33., Fortaleza, 1996. Anais. Fortaleza: SBZ, 1996. p.403-405.

HERLING, V.R. Efeitos de níveis de nitrogênio sobre algumas características fisiológicas e qualitativas dos cultivares Colonião e Centenário (Panicum maximum Jacq.). Jaboticabal, 1995. 125p. Tese (Doutorado) - Faculdade de Ciências Agrárias e Veterinárias, Universidade Estadual Paulista "Júlio de Mesquita Filho".

OLIVEIRA, J.B.; PRADO, H. Levantamento pedológico do Estado de São Paulo: quadrícula de São Carlos; II Memorial descritivo. Campinas: IAC, 1984. 188p. (Boletim Técnico, 98).

QUAGGIO, J.A. Resposta das culturas à calagem. In: SEMINÁRIO SOBRE CORRETIVOS AGRÍCOLAS, Piracicaba, 1983. Anais. Campinas: Fundação Cargill, 1985. p.123-154.

RAIJ, B. van. Avaliação da fertilidade do solo. Piracicaba: Associação Brasileira para Pesquisa da Potassa e do Fosfato, 1981. 142p.

RODRIGUES, L.R.A. Espécies forrageiras para pastagens: gramíneas. In: SIMPÓSIO SOBRE MANEJO DE PASTAGENS, 8., Piracicaba, 1986. Anais. Piracicaba: FEALQ, 1986. p.375388.

SAS Institute Inc., SAS/STAT User's guide, version 6, Fourth Edition, volume 2, Cary, NC: SAS Institute Inc., 1989. 846p.

SOARES FILHO, C.V. Variação sazonal de parâmetros bioquímico-fisiológicos em Brachiaria decumbens estabelecida em pastagem. Piracicaba, 1991. 110p. Dissertação (Mestrado) - Escola Superior de Agricultura "Luiz de Queiroz", Universidade de São Paulo.

SPAIN, J.M.; GUALDRON, R. Degradación e rehabilitación de pasturas. In: LASCANO, C.; SPAIN, J.M. (Ed.) Establecimiento y renovación de pasturas. Cali: CIAT, 1991. 426p.

TOLEDO, J.M.; SCHULTZE-KRAFT, R. Metodologia para la evaluación agronômica de pastos tropicales. In: TOLEDO, J.M. (Ed.) Manual para la evaluácion agronômica. Cali: CIAT, 1982. p.91-110.

VITTI, G.C.; LUZ, P.H.C. Calagem e uso do gesso agrícola em pastagens. In: SIMPÓSIO SOBRE ECOSSISTEMA DE PASTAGENS, 3., Jaboticabal, 1997. Anais. Jaboticabal: FCAV, UNESP, 1997. p.63-111.

WERNER, J.C.; MONTEIRO, F.A.; CARRIEL, J.M. Efeitos da calagem em capim Colonião (Panicum maximum Jacq.) estabelecido. Boletim da Indústria Animal, v.36, p.247-254, 1979.

WERNER, J.C.; PAULINO V.T.; CANTARELLA, H.; ANDRADE, N.O.; QUAGGIO, J.A. Forrageiras. In: RAIJ, B. van; CANTARELLA, H.; QUAGGIO, J.A.; FURLANI, A.M.C. Recomendações de adubação e calagem para o Estado de São Paulo. 2.ed. Campinas: Instituto Agronômico de Campinas, Fundação IAC, 1996. p.263-273.

ZIMMER, A.H.; MACEDO, M.C.M.; BARCELLOS, A.O.; KICHEL, A.V. Estabelecimento e recuperação de pastagens de Braquiária. In: SIMPÓSIO SOBRE MANEJO DE PASTAGEM, 11., Piracicaba, 1994. Anais. Piracicaba: FEALQ, 1994. p.107-151.

$\overline{\text { Recebido em } 02.10 .00}$ 